\title{
SCIENTIFIC REPORTS

\section{OPEN Prognostic factors and outcome of adult allogeneic hematopoietic stem cell transplantation patients admitted to intensive care unit during transplant hospitalization}

\author{
Christian S. Michel ${ }^{1}$, Daniel Teschner ${ }^{1}$, Irene Schmidtmann ${ }^{2}$, Matthias Theobald ${ }^{1}$, \\ Beate Hauptrock ${ }^{1}$, Eva M. Wagner-Drouet ${ }^{1,3}$ \& Markus P. Radsak $\mathbb{( i D}^{1,3^{*}}$
}

Patients undergoing allogeneic hematopoietic stem cell transplantation have a high morbidity and mortality, especially after admission to intensive care unit (ICU) during peri-transplant period. The objective of this study was to identify new clinical and biological parameters and validate prognostic scores associated with ICU, short-and long-term survival. Significant differences between ICU survivors and ICU non-survivors for the clinical parameters invasive mechanical ventilation, urine output, heart rate, mean arterial pressure, and amount of vasopressors have been measured. Among prognostic scores (SOFA, SAPSII, PICAT, APACHE II, APACHE IV) assessing severity of disease and predicting outcome of critically ill patients on ICU, the APACHE II score has shown most significant difference $(p=0.002)$ and the highest discriminative power (area under the ROC curve (AUC) 0.74). An elevated level of lactate at day of admission was associated with poor survival on ICU and the most significant independent parameter $(p<0.001)$. In our cohort kidney damage with low urine output has a highly relevant impact on ICU, short- and long-term overall survival. The APACHE II score was superior predicting ICU mortality compared to all other tested prognostic scores for patients on ICU during peritransplant period.

Allogeneic hematopoietic stem cell transplantation (allo-HSCT) offers a potential curative treatment for a variety of hematological diseases. However, the transplantation procedure is commonly connected to a variety of transplant-related factors such as patient age, intensity of conditioning, type of graft, presence of infections, many of which have significantly changed over the past decades ${ }^{1}$. The most common reasons for intensive care unit (ICU) admission after allo-HSCT are respiratory failure and septic shock. Other reported reasons for ICU admission include cardiac dysfunction, neurological disorders, and severe hemorrhage ${ }^{2,3}$. Despite advances in intensive care treatment and allo-HSCT, outcome of patients who need to be treated on ICU after allo-HSCT remains poor. After admission to ICU, in-hospital mortality of allo-HCST patients ranges from 53 to $75 \%$ with a 1 -year overall survival of 15 to $28 \%{ }^{4}$, much lower than the general overall 1-year survival of $60-70 \%$ in allo-HSCT recipients ${ }^{4,5}$. Unfortunately, several previously published studies often combined allogeneic and autologous stem cell transplanted patients and the related prognostic ICU scores like Sequential Organ Failure Assessment (SOFA) ${ }^{6}$, Simplified Acute Physiology Score II (SAPS II) ${ }^{7}$, and the Acute Physiology And Chronic Health Evaluation score II and IV (APACHE II and IV) ${ }^{8-10}$. Some studies found that these scoring systems underestimate the mortality of allo-HSCT patients, and yet others found that they are useful for estimating mortality in the ICU setting ${ }^{9,11-13}$. Recently, a new prognostic index tailored for critically ill allo-HSCT patients has been developed, the Prognostic Index for Critically Ill Allogeneic Transplantation Patients (PICAT score) ${ }^{14}$.

\footnotetext{
${ }^{1}$ Department of Hematology, Medical Oncology, \& Pneumology, University Medical Center of the Johannes Gutenberg University, Mainz, Germany. ${ }^{2}$ Institute of Medical Biostatistics, Epidemiology and Informatics (IMBEI), University Medical Center of the Johannes Gutenberg University, Mainz, Germany. ${ }^{3}$ These authors contributed equally: Eva M. Wagner-Drouet and Markus P. Radsak. *email: markus.radsak@unimedizin-mainz.de
} 


\begin{tabular}{|c|c|c|c|c|c|c|c|}
\hline & \multicolumn{2}{|c|}{ All patients, $n=78$} & \multicolumn{2}{|c|}{ ICU survivors, $n=44$} & \multicolumn{2}{|c|}{ ICU non-survivors, $n=34$} & \multirow{2}{*}{$\begin{array}{l}\mathbf{p} \text {-Value } \\
0.270\end{array}$} \\
\hline Sex, male, n (\%) & 45 & $(57.7)$ & 23 & \begin{tabular}{|l|l}
$(52.3)$ \\
\end{tabular} & 22 & (64.7) & \\
\hline Age, years, median (IQR) & 54.4 & $(45.2-61.1)$ & 51.4 & $(45.4-60.8)$ & 58.5 & $(46.6-60.8)$ & 0.579 \\
\hline BMI, median (IQR) & 23.7 & $(21.6-26.9)$ & 23.1 & $(21.5-26.2)$ & 24.5 & $(22.3-27.4)$ & 0.247 \\
\hline \multirow{4}{*}{$\begin{array}{l}\text { Underlying disease } \\
\text {-Acute leukemia, } \mathrm{n}(\%) \\
\text {-Myeloproliferative disease and MDS, n (\%) } \\
\text {-Lymphoma and Multiple Myeloma, n (\%) } \\
\text {-Aplastic anemia, } \mathrm{n}(\%)\end{array}$} & 59 & $(75.6)$ & 31 & $(70.5)$ & 28 & $(82.4)$ & \multirow{4}{*}{0.125} \\
\hline & 13 & $(16.7)$ & 10 & $(22.7)$ & 3 & $(8.8)$ & \\
\hline & 4 & $(5.1)$ & 1 & $(2.3)$ & 3 & $(8.8)$ & \\
\hline & 2 & $(2.6)$ & 2 & $(4.5)$ & 0 & $(0)$ & \\
\hline \multirow{2}{*}{$\begin{array}{l}\text { Remission status } \\
\text {-Refractory disease, n (\%) } \\
\text { Conditioning regimen } \\
\text {-MA, n (\%) } \\
\text {-RIC and NMA, n (\%) } \\
\text {-FLAMSA-RIC, n (\%) }\end{array}$} & 23 & $(29.5)$ & 14 & $(31.8)$ & 9 & $(26.5)$ & \multirow[b]{2}{*}{$\begin{array}{l}0.608 \\
0.965\end{array}$} \\
\hline & $\begin{array}{l}24 \\
33 \\
21\end{array}$ & $\begin{array}{l}(30.8) \\
(42.3) \\
(26.9)\end{array}$ & $\begin{array}{l}13 \\
19 \\
12\end{array}$ & $\begin{array}{l}(29.5) \\
(43.2) \\
(27.3)\end{array}$ & $\begin{array}{l}11 \\
14 \\
9\end{array}$ & $\begin{array}{l}(32.4) \\
(41.2) \\
(26.4)\end{array}$ & \\
\hline \multirow{2}{*}{$\begin{array}{l}\text { Source of stem cells } \\
\text {-Peripheral blood, } \mathrm{n}(\%) \\
\text {-Bone marrow, } \mathrm{n}(\%)\end{array}$} & 76 & (97.4) & 42 & (95.5) & 34 & $(100)$ & \multirow{2}{*}{0.208} \\
\hline & 2 & (2.6) & 2 & $(4.5)$ & 0 & (0) & \\
\hline \multirow{3}{*}{$\begin{array}{l}\text { Graft } \\
\text {-HLA identical sibling, n (\%) } \\
\text {-HLA matched unrelated donor, n (\%) } \\
\text {-HLA-mismatched, n (\%) }\end{array}$} & 11 & $(14.1)$ & 7 & $(15.9)$ & 4 & $(11.8)$ & \multirow{3}{*}{0.339} \\
\hline & 53 & $(68.0)$ & 27 & $(61.4)$ & 26 & $(76.4)$ & \\
\hline & 14 & $(17.9)$ & 10 & $(22.7)$ & 4 & $(11.8)$ & \\
\hline $\begin{array}{l}\text { CMV } \\
\text {-Positive, n (\%) }\end{array}$ & 51 & $(65.4)$ & 29 & $(70.5)$ & 22 & $(64.7)$ & 0.912 \\
\hline HCT-CI score, median (IQR) & 3 & $(2.0-5.0)$ & 3 & $(2.0-5.0)$ & 3 & $(1.0-5.0)$ & 0.485 \\
\hline $\begin{array}{l}\text { Time from Hospital to ICU admission (d), } \\
\text { median (IQR) Reason for ICU admission } \\
\text {-Sepsis, } \mathrm{n}(\%) \\
\text {-Respiratory failure, } \mathrm{n}(\%) \\
\text {-Cardiac arrest/arrhytmia,n (\%) } \\
\text {-Post-surgery, } \mathrm{n}(\%) \\
\text {-Neurological disorders, } \mathrm{n}(\%) \\
\text {-Severe bleeding, } \mathrm{n}(\%)\end{array}$ & $\begin{array}{l}19 \\
28 \\
59 \\
10 \\
3 \\
20 \\
5\end{array}$ & $\begin{array}{l}(11.8-27.0) \\
(35.9) \\
(75.6) \\
(7.8) \\
(3.8) \\
(25.6) \\
(6.4)\end{array}$ & $\begin{array}{l}19.5 \\
12 \\
32 \\
6 \\
3 \\
12 \\
5\end{array}$ & $\begin{array}{l}(11.8-27.0) \\
(27.3) \\
(72.7) \\
(13.6) \\
(6.8) \\
(27.3) \\
(11.4)\end{array}$ & $\begin{array}{l}18 \\
16 \\
27 \\
4 \\
0 \\
8 \\
0\end{array}$ & $\begin{array}{l}(13.3-26.8) \\
(47.1) \\
(79.4) \\
(11.8) \\
(0.0) \\
(23.5) \\
(0.0)\end{array}$ & $\begin{array}{l}0.964 \\
0.071 \\
0.495 \\
0.806 \\
0.120 \\
0.707 \\
0.042\end{array}$ \\
\hline
\end{tabular}

Table 1. Baseline characteristics of all patients admitted to ICU. Abbreviations: BMI = Body mass index; MDS = Myelodysplastic syndrome; MA = Myeloablative; RIC = Reduced intensity conditioning; NMA = Nonmyeloablative; FLAMSA = Induction chemotherapy before conditioning chemotherapy; HLA = Human Leukocyte Antigen; CMV = Cytomegalivirus; HCT-CI = Hematopoietic Cell Transplantation-specific Comorbidity Index.

The primary objective of the study was to assess short-and long-term outcomes, to identify new clinical and biological predictors as well as the comparison of new and established prognostic factors associated with ICU, hundred day and 1-year mortality for allo-HSCT patients admitted to ICU during the peri-transplant period.

\section{Results}

Patient characteristics. During the study period 544 patients received a first allo-HSCT of whom 81 (14.9\%) patients had to be transferred to ICU during their transplant hospitalization. Three patients who were admitted on ICU during conditioning chemotherapy and died before allo-HSCT were excluded from further analysis. The main characteristics of the total cohort and the subgroups (ICU survivors vs. ICU non-survivors) are shown in Table 1. Median age at time of hematopoietic stem cell transplantation was 54.4 years (interquartile range (IQR) 45.2-61.1). Main underlying diseases were acute leukemias with $75.6 \%$ as well as myeloproliferative diseases and myelodysplastic syndrome (MDS) with $16.7 \%$. The hematopoietic malignancy had no influence on ICU survival (ns).

About $29.5 \%$ of patients were transplanted with refractory disease. Conditioning regimen was myeloablative in $30.8 \%$ and $26.9 \%$ of patients received FLAMSA as an induction part of the reduced intensity conditioning regimen (FLAMSA-RIC) ${ }^{15}$. The FLAMSA protocol combines a four-day salvage chemotherapy consisting of daily fludarabine, amsacrine and cytarabine, followed by three days of pause with the reduced-intensity conditioning regimen. Peripheral blood stem cells were in $97.4 \%$ the source of the stem cell graft and the majority of patients $(68 \%)$ had a HLA matched unrelated donor. Gender, age, body mass index (BMI), remission status, conditioning regimen, source of stem cells, donor type and cytomegalovirus (CMV) status were not significantly different between ICU survivors and ICU non-survivors.

The median time from hospital admission to ICU admission was 19 days (IQR 11.8-27) and patients had a median HCT-CI score of 3 (IQR 2-5) before allo-HSCT. The single or multifactorial reasons of ICU transfer were respiratory failure $(72.7 \%$ in ICU survivors, $79.4 \%$ in ICU non-survivors, $p=0.495)$, followed by sepsis $(27.3 \%$ in ICU survivors, $47.1 \%$ in ICU non-survivors, $p=0.071)$ and severe neurological disorders (27.3 in ICU survivors, $23.5 \%$ in ICU non-survivors, $p=0.707)$. Occurrence of severe bleeding ( $11.4 \%$ in ICU survivors, $0 \%$ in ICU non-survivors, $p=0.042$ ) was more frequently in ICU survivors. No patient had a recurrent or progressive disease after HSCT when admitted to ICU. 
Clinical and laboratory parameters. During first 24 hours of ICU admission, non-invasive ventilation (NIV) as a first approach was used in $17 \%$ of patients and switched in almost half of them to invasive mechanical ventilation (IMV) after NIV failure. Altogether, invasive mechanical ventilation was initiated in $60 \%$ of all patients $(n=47)$ with a median Horowitz Index (ratio of partial pressure of oxygen in blood and fraction of oxygen in the inhaled air- $\mathrm{PaO}_{2} / \mathrm{FiO}_{2}$ ) of 160 (IQR 114.5-273.0). Median duration of IMV was 17 days (IQR 8.5-29) and ICU survivors had lower frequency of IMV ( $45.5 \%$ vs $79.4 \%, p=0.002)$.

A total of $68 \%(n=53)$ of the patients presented with acute kidney injury (AKI) and RRT was initiated in almost half of these patients $(n=24)$. In addition, level of creatinine was significantly higher in ICU non-survivors (median $2.21 \mathrm{mg} / \mathrm{dl}$ vs $1.59 \mathrm{mg} / \mathrm{dl}, p=0.029$ ) and the urine output in the first 24 hours after admission was significantly lowered (median $1050 \mathrm{ml} / \mathrm{d}$ vs $2085 \mathrm{ml} / \mathrm{d}, p=0.003$ ). Median duration of RRT was 7.5 days (IQR 4-15). Urine output in 24 hours after admission to ICU of 365d survivors was $4055 \mathrm{ml} / \mathrm{d}$ (IQR 2048-5015) and of 365d non-survivors $1290 \mathrm{ml} / \mathrm{d}$ (IQR 588-2350). The urine output was the most significant clinical and laboratory parameter $(p<0.001)$ in $365 \mathrm{~d}$ mortality analysis with an AUC of $0.79(0.66-0.92,95 \% \mathrm{CI})$. Median fluid overload was $4.3 \mathrm{~kg}$ (IQR 1.4-6.9) after ICU admission compared to hospital admission but had no impact on ICU survival (ns).

ICU non-survivors suffered from higher heart rate (median $135 \mathrm{bpm}$ vs $123 \mathrm{bpm}, p=0.019$ ) and lower mean arterial blood pressure (median $60.0 \mathrm{mmHG}$ vs $63.0 \mathrm{mmHg}, p=0.024$ ) than ICU survivors. Treatment with norepinephrine was necessary in $74 \%$ of patients and ICU survivors needed lower doses of norepinephrine (median $0.4 \mathrm{mg} / \mathrm{h}$ vs $0.9 \mathrm{mg} / \mathrm{h}, p=0.011$ ). In the same line, ICU non-survivors showed higher level of lactate (median $4.3 \mathrm{mmol} / \mathrm{l}$ vs $1.7 \mathrm{mmol} / \mathrm{l}, p<0.001$ ), while $\mathrm{pH}$ (median $7.25 \mathrm{vs} 7.31 ; p=0.015$ ), albumin (median $22 \mathrm{~g} / \mathrm{l} \mathrm{vs} 24 \mathrm{~g} / \mathrm{l}$, $\mathrm{p}=0.026$ ) and bicarbonate (median $18.6 \mathrm{mmol} / \mathrm{l}$ vs $20.96 \mathrm{mmol} / \mathrm{l}, p=0.043$ ) were significantly lowered. Lactate showed best discriminative power among all clinical and laboratory parameters (AUC 0.75, 0.64-0.86 95\% CI) for ICU mortality. A cut off value of $3.35 \mathrm{mmol} / \mathrm{L}$ has been calculated by using Youden's $J$ statistic. All significant clinical and laboratory parameters are listed in Table 2.

Procalcitonin (PCT) at admission was not significantly different between ICU survivors and non-survivors, but a simple linear regression analysis has demonstrated that patients admitted to ICU before and close around the transplant date had higher PCT levels than patients admitted to ICU in later time of transplantation (adjusted $\left.\mathrm{R}^{2}=0.242, \mathrm{p}<0.001\right)$.

Prognostic scores. Median SOFA and SAPS II score for all patients were 14.0 (IQR 12.0-17.0) and 64.5 (IQR 53.0-81.3), respectively. Our analysis showed significant differences between ICU-survivors and ICU non-survivors for SOFA score, but not SAPS II score (SOFA, median 13.5 vs 16.0, $p=0.010$; SAPS II, median 56 vs $70, p=0.131)$. APACHE II and APACHE IV score showed even higher significant differences between ICU-survivors and non-survivors (APACHE II, median 27 vs 31, $p=0.002$; APACHE IV, median 93 vs 111, $p=0.007)$. Analysis of ROC curves showed that among all prognostic scores APACHE II had the best discriminative power (AUC $0.74,0.63-0.8495 \%$ CI) followed by SOFA score (AUC 0.70, 0.59-0.82 95\% CI). An AUC of 0.74 indicates good discriminative power for APACHE II while the AUC of 0.66 indicates a moderate discriminative power for APACHE IV. In contrast, PICAT score was not significantly different between ICU-survivors and non-survivors (median 4.0 vs $3.9, p=0.102$ ) and had the lowest discriminative power (AUC $0.58,0.45-0.7195 \%$ CI). In the cohort, ICU mortality of patients with PICAT score $0-2(n=9),>2-4(n=34)$ and $>4(n=35)$ were $33 \%, 44 \%$ and $46 \%$. AUC for ICU mortality for APACHE II was not significantly larger $(p=0.082)$ than the AUC of the PICAT score (Fig. 1).

The logistic regression model revealed significant effects on 1-year survival for the prognostic scores APACHE II $(p=0.017)$ and APACHE IV ( $p=0.016)$, whereas SOFA, SAPS II and PICAT score showed no significant effect. APACHE II score showed best discriminative power among all prognostic scores (AUC 0.71, 0.57-0.84 95\% CI) for the 1-year survival.

Short- and long-term survival. Of 78 patients admitted to ICU, 44 patients $(56.4 \%)$ could be discharged from ICU back to our transplant unit. In the further course, 19 patients had a second admission to ICU in median 17 days after last discharge (IQR 6-73). The 100d and 365d survival rates of all ICU treated patients were $42.3 \%$ and $23.1 \%$, respectively. Median overall surivival for all patients was 65 days (IQR 28-351) Fig. 2A. All patients needing RRT $(n=6)$ with hemodynamic support at the day of ICU admission died within in the first year after transplantation. Patients with IMV and RRT had the second worst survival. Multiple comparison of survival curves have shown that patients requiring no IMV and RRT at the day of ICU admission had a significant better overall survival compared to patients with IMV and RRT $(p=0.013)$ Fig. 2B. From 44 patients after first ICU admission 13 patients died from severe infectious complications/graft-versus-host disease (GvHD), 12 from relapse of the hematological disease and 4 from severe brain damage. Vast majority $(n=26)$ was dying in the first year after transplantation, only 3 patients died after the first year.

\section{Discussion}

This study presents the outcome in relation to prognostic scores, as well as clinical and laboratory parameters in a single-center cohort of allo-HSCT patients admitted to ICU during peri-transplant period. The study excluded allo-HSCT patients admitted to ICU in later course after transplantation and inhibited major influence of community-acquired infections, relapse and acute or chronic GvHD complications. Additionally, autologous HSCT patients on ICU were excluded as their outcomes seem to be better and their transplantation- and disease-related factors are different than those of allo-HSCT patients ${ }^{16-18}$. Therefore, a mostly homogenous cohort of allo-HSCT patients under severe and life-threatening conditions has been investigated. 


\begin{tabular}{|c|c|c|c|c|c|c|c|}
\hline & \multicolumn{2}{|c|}{ All patients, $n=78$} & \multicolumn{2}{|c|}{ ICU survivors, $n=44$} & \multicolumn{2}{|c|}{ ICU non survivors, $\mathrm{n}=34$} & p-Value \\
\hline \multicolumn{8}{|l|}{ Prognostic Scores } \\
\hline $\begin{array}{l}\text {-SOFA, median (IQR) } \\
\text {-APACHE II, median (IQR) } \\
\text {-APACHE IV, median (IQR) } \\
\text {-SAPS II, median (IQR) } \\
\text {-PICAT, median (IQR) }\end{array}$ & $\begin{array}{l}14 \\
29 \\
102 \\
65 \\
4.0\end{array}$ & $\begin{array}{l}(12-17) \\
(25-33) \\
(77-126) \\
(53-81) \\
(3.0-5.0)\end{array}$ & $\begin{array}{l}13.5 \\
27 \\
93 \\
56 \\
4.0\end{array}$ & $\begin{array}{l}(11.0-16.0) \\
(20-31) \\
(69.0-115.0) \\
(46.8-73.3) \\
(3.0-4.2)\end{array}$ & $\begin{array}{l}16.0 \\
31 \\
111 \\
70 \\
3.9\end{array}$ & $\begin{array}{l}(14.0-18.0) \\
(27-37) \\
(93-142) \\
(53-78) \\
(3.1-5.3)\end{array}$ & $\begin{array}{l}0.010 \\
0.002 \\
0.007 \\
0.131 \\
0.213\end{array}$ \\
\hline \multicolumn{8}{|l|}{ Clinical parameters } \\
\hline $\begin{array}{l}\text {-Mechanical ventilation, } \mathrm{n}(\%) \\
\text {-RRT, } \mathrm{n}(\%) \\
\text {-Urine output (ml/d), median (IQR) } \\
\text {-Heart rate (bpm), median (IQR) } \\
\text {-Mean arterial pressure (mmHg), median (IQR) } \\
\text {-Norepinephrine (mg/h), median (IQR) }\end{array}$ & $\begin{array}{l}47 \\
24 \\
1530 \\
126 \\
61.0 \\
0.6\end{array}$ & $\begin{array}{l}(60.3) \\
(30.8) \\
(823-3433) \\
(112-138) \\
(56.0-68.3) \\
(0.0-1.2)\end{array}$ & $\begin{array}{l}20 \\
10 \\
2085 \\
123 \\
63.0 \\
0.4\end{array}$ & $\begin{array}{l}(45.5) \\
(22.7) \\
(1008-3983) \\
(105-132) \\
(56.0-72.8) \\
(0.0-0.75)\end{array}$ & $\begin{array}{l}27 \\
14 \\
1050 \\
135 \\
60.0 \\
0.9\end{array}$ & $\begin{array}{l}(79.4) \\
(41.2) \\
(288-1775) \\
(119-144) \\
(53.8-63.5) \\
(0.4-2.15)\end{array}$ & $\begin{array}{l}0.002 \\
0.080 \\
0.003 \\
0.019 \\
0.024 \\
0.011\end{array}$ \\
\hline \multicolumn{8}{|l|}{ Laboratory parameters } \\
\hline $\begin{array}{l}\text {-Albumin (g/l), median (IQR) } \\
\text {-Lactate (mmol/l), median (IQR) } \\
\text {-pH, median (IQR) } \\
\text {-Bicarbonate (mmol/l), median (IQR) } \\
\text {-Creatinine (mg/dl), median (IQR) }\end{array}$ & $\begin{array}{l}23.0 \\
2.3 \\
7.28 \\
19.5 \\
1.97\end{array}$ & $\begin{array}{l}(20.5-26.5) \\
(1.4-4.6) \\
(7.22-7.37) \\
(17.7-22.2) \\
(1.18-2.75)\end{array}$ & $\begin{array}{l}24 \\
1.7 \\
7.31 \\
20.9 \\
1.59\end{array}$ & $\begin{array}{l}(22.0-28.0) \\
(1.1-2.6) \\
(7.25-7.40) \\
(18.7-22.5) \\
(1.10-2.47)\end{array}$ & $\begin{array}{l}22 \\
4.3 \\
7.25 \\
18.6 \\
2.21\end{array}$ & $\begin{array}{l}(19.0-25.5) \\
(2.6-6.2) \\
(7.17-7.30) \\
(15.6-21.1) \\
(1.65-2.83)\end{array}$ & $\begin{array}{l}0.026 \\
<0.001 \\
0.015 \\
0.043 \\
0.029\end{array}$ \\
\hline
\end{tabular}

Table 2. Prognostic scores, clinical and laboratory parameters. Abbreviations: RRT $=$ Renal replacement therapy.

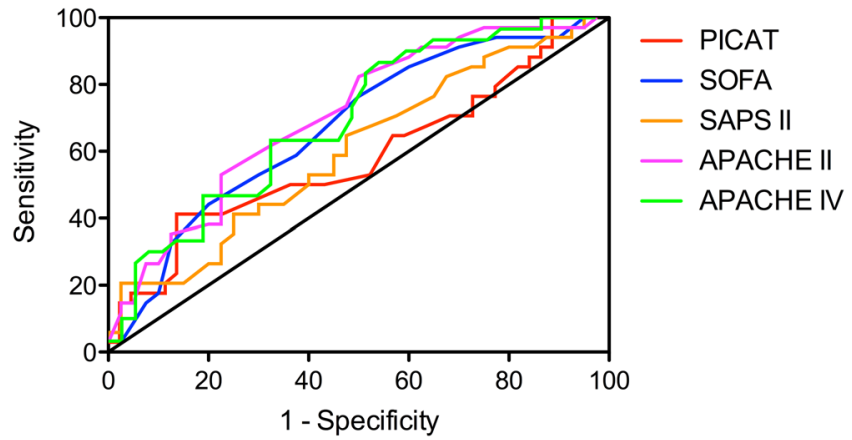

Figure 1. ROC curves for prognostic scores. ROC curves for SOFA, SAPS II, APACHE II, APACHE IV and PICAT score predicting ICU mortality.
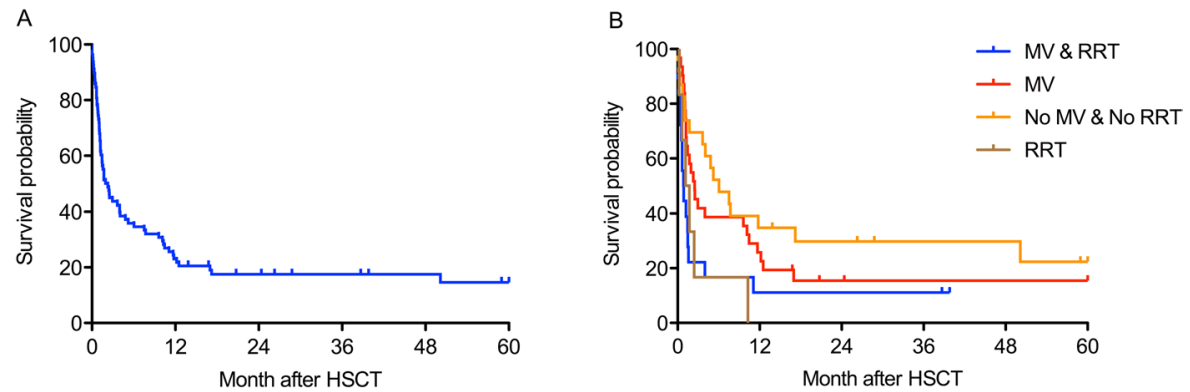

Figure 2. Overall survival (A) Overall survival; (B) Overall survival of subgroups (MV \& RRT, MV, No MV \& No RRT, RRT).

Our ICU admission rate of $14.9 \%$ was low compared to previous published studies. In addition, the median time from HSCT to ICU admission was with 8.5 (IQR 0.0-16) days also shorter than previously described. The discrepancy is mainly caused by the exclusion of allo-HSCT patients in late course after transplantation. The ICU admission of all allo-HSCT patients after transplantation in our center (33\%) compared with other centers has shown similar admission rates ${ }^{3,19,20}$. As observed for other critically ill patients, ICU survival of allo-HSCT recipients has improved over the last decades. The ICU survival rate of $56.4 \%$ and in hospital mortality of $58.9 \%$ compares favorably with previous reports ${ }^{8,10,12,21,22}$. Unfortunately, 1-year survival with $23.1 \%$ remains poor and is in the range previously reported.

Consistent with other reports, several factors were predictive of mortality on ICU during the ICU admission including invasive mechanical ventilation, mean arterial pressure norepinephrine amount and heart rate re, $^{49,23}$. 
Sex, age, body mass index (BMI) and disease related factors have shown no significant role in determining ICU outcome. Among all clinical and laboratory parameters lactate was the most significant one. Unfortunately, none of the tested prognostic scores (SOFA, SAPS II, APACHE II and APACHE IV) includes lactate as a parameter. Increased blood lactate levels have been related to morbidity and mortality in different patient groups ${ }^{24,25}$. Thus, lactate measurement might be an additional laboratory parameter for predicting ICU mortality and evaluated in further studies. Measurement of procalcitonin (PCT) at date of admission had no prognostic power in our cohort. Higher levels of PCT during conditioning chemotherapy and around transplantation date are probably triggered by anti-thymocyte gobulin (ATG) as reported by Brodska et al. and have no predictive value of future infectious complications ${ }^{26}$. Surprisingly, regarding 1 -year overall survival urine output during the first 24 hours after ICU admission was the most significant clinical and laboratory parameter. Acute kidney injury is a risk factor for mortality and has been shown in a number of previously published studies ${ }^{27-29}$. Reduced urine output seems to be highly relevant for short- and long-term survival in allo-HSCT patients on ICU during transplant hospitalization. Our study shows the high relevance of the urine output as a marker of long-term outcome of allo-HSCT patients admitted to ICU during peri-transplant period.

In our cohort the APACHE II score showed best discriminative power predicting ICU mortality followed by APACHE IV score. Unfortunately, the newly developed PICAT score was not valuable predicting mortality on ICU as well as short-and long-term survival of allo-HSCT patients admitted to ICU during peri-transplant period. The PICAT score was developed by inclusion of all ICU patients after allo-HSCT. Bayraktar et al. have described an increased mortality with increased level of PICAT score up to $91 \%$ with a PICAT score higher than $4^{14}$, whereby in our cohort patients with a score of more than 4 had a mortality of $46 \%$. Allo-HSCT patients in early and late time after transplantation might face different levels of laboratory parameters, time to ICU from hospital admission as well as influence of relapse, acute and chronic GvHD.

Our study has certain limitations, primarily its retrospective nature. All transplantation- and disease-related factors, clinical and laboratory parameters were collected retrospectively. Second, this is a single-center study and criteria for ICU admission might vary from one to another center partially in a substantial manner. Therefore, uniform criteria for ICU admission, laboratory parameters and prognostic scores should be tested and validated in prospective multicenter studies.

In conclusion, this study demonstrated that a considerable number of patients after allo-HSCT has to be transferred to the ICU during transplantation. Despite ICU survival of allo-HSCT patients improved over the last decades long term outcome still remains poor after ICU discharge. In our cohort of peri-transplant patients the APACHE II score has shown to be superior to all other tested prognostic scores, even to the newly developed PICAT score. Our findings might be helpful for designing prospective multicenter studies and prognostic scores by inclusion of new and established clinical and laboratory parameters. For the development of a prognostic score for critically ill allo-HSCT patients during transplant hospitalization, the inclusion of urine output and lactate should be highly considered. High-risk patients could be identified and treatment performed according to their risk stratification. Additionally, enhanced assessment of mortality of critically ill patients might be helpful in conversations about prognosis with relatives. Furthermore, therapies preventing and treating acute kidney injury as well as research in critical care management may substantially improve patients' prognosis after allo-HSCT.

\section{Material and Methods}

Patients. We retrospectively reviewed all consecutive adult patients ( $>18$ years) with hematological malignancy who underwent a first allo-HSCT at our institution and had to be transferred to ICU during peri-transplant period (d-7 to $d+30)$ between January 2010 and January 2017. For patients with multiple ICU admissions, only the first ICU admission was analyzed. Allogeneic HSCT was performed according to EBMT and JACIE guidelines (https://www.ebmt.org/accreditation/jacie-standards). The study was conducted in accordance with Good Clinical Practice Guidelines and the amended Declaration of Helsinki (1964). The study has been approved by the Landesaerztekammer Rhineland-Palatine Ethics Committee (Approval ID:2018-13837) and the Institutional Review Board waived the need for informed consent. The patients transferred to ICU presented a severe and life-threatening condition necessitating single or combinatory need for mechanical ventilation (MV), renal replacement therapy (RRT) with hemodynamic support, uncontrolled bleedings, strong impairment of vigilance or/and continuous invasive monitoring of vital parameters due to septic shock. Treatment of patients requiring only low dose amount of vasopressors was performed in the transplant unit (norepinephrine $<0,3 \mathrm{mg} / \mathrm{h}$ ).

Clinical variables like age, sex, size, weight, underlying disease, HSCT parameters, and conditioning regimen, reason for ICU admission have been taken from patient chart. Definitions for myeloablative conditioning are according to the CIBMTR working committee ${ }^{30}$. The standardized calculation of the Hematopoietic Cell Transplant-Co Morbidity Index (HCT-CI) for patients has been introduced in 2015 in our department ${ }^{31}$. For patients before 2015 the HCT-CI score had to be calculated retrospectively from patient chart.

Clinical variables (Glasgow coma scale, non-invasive/invasive mechanical ventilation, renal replacement therapy, fluid balance, urine output, body temperature, heart rate, blood pressure, respiratory rate, peripheral oxygen saturation, norepinephrine consumption) and laboratory values (white blood cells, thrombocytes, hematocrit, international normalized ratio (INR), activated partial thromboplastin time (aPTT), fibrinogen, sodium, potassium, bicarbonate, creatinine, blood urea nitrogen, alanine aminotransferase (ALT), aspartate aminotransferase (AST), bilirubin, lactate dehydrogenase (LDH), albumin, total protein, blood sugar, C-reactive protein, procalcitonin, lactate, $\mathrm{pH}, \mathrm{pO}_{2}, \mathrm{pCO}_{2}$ ) during the first 24 hours on ICU were monitored. Based on the recorded variables the SOFA, the SAPS II, the APACHE II and IV and the PICAT score have been calculated at admission to ICU as previously described ${ }^{6,7,14,32,33}$.

Overall survival is defined as the time from the day of hematopoietic stem cell transplantation to death from any cause. The minimal and median follow-up time for ICU survivors was 14 and 38 months, respectively. 
Statistical analysis. Categorical variables were reported as numbers and percentages, and continuous variables as median and interquartile range. Correlations with ICU mortality were evaluated using the Chi-square test for categorical data and the Mann-Whitney $U$ test for continuous variables. For the 1-year survival a binary logistic regression model was used, this was possible as there was no censoring before one year. Survival curves were obtained using the Kaplan-Meier method. They were compared using the log-rank test and a BonferroniHolm post-hoc analysis. $P<0.05$ was deemed to indicate statistical significance. To assess each prognostic score, discrimination was analyzed by obtaining the area under the receiver operating characteristic curve (AUC). Comparisons between two curves were tested for statistical significance by using the method described by Hanley and $\mathrm{Mc} \mathrm{Neil}^{34}$. The statistical analyses were performed using the $\mathrm{IBM}^{\circledR}$ SPSS $^{\circledR}$ Statistics version 23 and GraphPad Prism ${ }^{\circledR}$ version 5.

Received: 7 June 2019; Accepted: 8 December 2019;

Published online: 27 December 2019

\section{References}

1. Gooley, T. A. et al. Reduced mortality after allogeneic hematopoietic-cell transplantation. The New England journal of medicine 363, 2091-2101 (2010).

2. Benz, R., Schanz, U., Maggiorini, M., Seebach, J. D. \& Stussi, G. Risk factors for ICU admission and ICU survival after allogeneic hematopoietic SCT. Bone marrow transplantation 49, 62-65 (2014).

3. Pene, F. et al. Outcome of critically ill allogeneic hematopoietic stem-cell transplantation recipients: a reappraisal of indications for organ failure supports. J Clin Oncol 24, 643-649 (2006).

4. Bayraktar, U. D. \& Nates, J. L. Intensive care outcomes in adult hematopoietic stem cell transplantation patients. World J Clin Oncol 7, 98-105 (2016).

5. Hahn, T. et al. Significant improvement in survival after allogeneic hematopoietic cell transplantation during a period of significantly increased use, older recipient age, and use of unrelated donors. J Clin Oncol 31, 2437-2449 (2013).

6. Vincent, J. L. et al. The SOFA (Sepsis-related Organ Failure Assessment) score to describe organ dysfunction/failure. On behalf of the Working Group on Sepsis-Related Problems of the European Society of Intensive Care Medicine. Intensive Care Med 22, 707-710 (1996).

7. Le Gall, J. R., Lemeshow, S. \& Saulnier, F. A new Simplified Acute Physiology Score (SAPS II) based on a European/North American multicenter study. JAMA 270, 2957-2963 (1993).

8. Boyaci, N. et al. The intensive care management process in patients with hematopoietic stem cell transplantation and factors affecting their prognosis. Hematology 19, 338-345 (2014).

9. Afessa, B., Tefferi, A., Dunn, W. F., Litzow, M. R. \& Peters, S. G. Intensive care unit support and Acute Physiology and Chronic Health Evaluation III performance in hematopoietic stem cell transplant recipients. Critical care medicine 31, 1715-1721 (2003).

10. Depuydt, P. et al. Outcome in critically ill patients with allogeneic BM or peripheral haematopoietic SCT: a single-centre experience. Bone marrow transplantation 46, 1186-1191 (2011).

11. Afessa, B. \& Azoulay, E. Critical care of the hematopoietic stem cell transplant recipient. Crit Care Clin 26, 133-150 (2010).

12. Neumann, F. et al. The sepsis-related Organ Failure Assessment (SOFA) score is predictive for survival of patients admitted to the intensive care unit following allogeneic blood stem cell transplantation. Annals of hematology 87, 299-304 (2008).

13. Gilbert, C., Vasu, T. S. \& Baram, M. Use of mechanical ventilation and renal replacement therapy in critically ill hematopoietic stem cell transplant recipients. Biology of blood and marrow transplantation: journal of the American Society for Blood and Marrow Transplantation 19, 321-324 (2013).

14. Bayraktar, U. D. et al. Prognostic Index for Critically Ill Allogeneic Transplantation Patients. Biology of blood and marrow transplantation: journal of the American Society for Blood and Marrow Transplantation 23, 991-996 (2017).

15. Schmid, C., Schleuning, M., Ledderose, G., Tischer, J. \& Kolb, H. J. Sequential regimen of chemotherapy, reduced-intensity conditioning for allogeneic stem-cell transplantation, and prophylactic donor lymphocyte transfusion in high-risk acute myeloid leukemia and myelodysplastic syndrome. J Clin Oncol 23, 5675-5687 (2005).

16. Spoerl, S. et al. Characteristics and outcome of patients presenting to the emergency department after autologous/allogeneic stem cell transplantation. Eur J Emerg Med 24, 435-442 (2017).

17. Trinkaus, M. A. et al. Predictors of mortality in patients undergoing autologous hematopoietic cell transplantation admitted to the intensive care unit. Bone marrow transplantation 43, 411-415 (2009).

18. Michel, C. S., Teschner, D., Wagner, E. M., Theobald, M. \& Radsak, M. P. Diagnostic value of sTREM-1, IL-8, PCT, and CRP in febrile neutropenia after autologous stem cell transplantation. Annals of hematology 96, 2095-2101 (2017).

19. Lueck, C. et al. Improved short- and long-term outcome of allogeneic stem cell recipients admitted to the intensive care unit: a retrospective longitudinal analysis of 942 patients. Intensive Care Med 44, 1483-1492 (2018).

20. Lengline, E. et al. Changes in intensive care for allogeneic hematopoietic stem cell transplant recipients. Bone marrow transplantation 50, 840-845 (2015).

21. Bayraktar, U. D. et al. Hematopoietic cell transplantation-specific comorbidity index predicts inpatient mortality and survival in patients who received allogeneic transplantation admitted to the intensive care unit. J Clin Oncol 31, 4207-4214 (2013).

22. Kim, S. W. et al. Feasibility of acute physiology and chronic health evaluation (APACHE) II and III score-based screening in patients receiving allogeneic hematopoietic stem-cell transplantation. Transplantation 75, 566-570 (2003).

23. Mayer, S., Pastores, S. M., Riedel, E., Maloy, M. \& Jakubowski, A. A. Short- and long-term outcomes of adult allogeneic hematopoietic stem cell transplant patients admitted to the intensive care unit in the peritransplant period. Leuk Lymphoma 58, 382-390 (2017).

24. Filho, R. R. et al. Blood Lactate Levels Cutoff and Mortality Prediction in Sepsis-Time for a Reappraisal? a Retrospective Cohort Study. Shock 46, 480-485 (2016).

25. Mikkelsen, M. E. et al. Serum lactate is associated with mortality in severe sepsis independent of organ failure and shock. Critical care medicine 37, 1670-1677 (2009).

26. Brodska, H. et al. Marked increase of procalcitonin after the administration of anti-thymocyte globulin in patients before hematopoietic stem cell transplantation does not indicate sepsis: a prospective study. Critical care 13, R37 (2009).

27. Brivet, F. G., Kleinknecht, D. J., Loirat, P. \& Landais, P. J. Acute renal failure in intensive care units-causes, outcome, and prognostic factors of hospital mortality; a prospective, multicenter study. French Study Group on Acute Renal Failure. Critical care medicine 24, 192-198 (1996).

28. Hoste, E. A. et al. RIFLE criteria for acute kidney injury are associated with hospital mortality in critically ill patients: a cohort analysis. Critical care 10, R73 (2006).

29. Kersting, S., Koomans, H. A., Hene, R. J. \& Verdonck, L. F. Acute renal failure after allogeneic myeloablative stem cell transplantation: retrospective analysis of incidence, risk factors and survival. Bone marrow transplantation 39, 359-365 (2007).

30. Bacigalupo, A. et al. Defining the intensity of conditioning regimens: working definitions. Biology of blood and marrow transplantation: journal of the American Society for Blood and Marrow Transplantation 15, 1628-1633 (2009). 
31. Sorror, M. L. et al. Hematopoietic cell transplantation (HCT)-specific comorbidity index: a new tool for risk assessment before allogeneic HCT. Blood 106, 2912-2919 (2005).

32. Knaus, W. A., Draper, E. A., Wagner, D. P. \& Zimmerman, J. E. APACHE II: a severity of disease classification system. Critical care medicine 13, 818-829 (1985).

33. Zimmerman, J. E., Kramer, A. A., McNair, D. S. \& Malila, F. M. Acute Physiology and Chronic Health Evaluation (APACHE) IV: hospital mortality assessment for today's critically ill patients. Critical care medicine 34, 1297-1310 (2006).

34. Hanley, J. A. \& McNeil, B. J. A method of comparing the areas under receiver operating characteristic curves derived from the same cases. Radiology 148, 839-843 (1983).

\section{Acknowledgements}

This project was supported by the "Universitäres Centrum für Tumorerkrankungen" (UCT) of the University Medical Center Mainz. The study was supported by the Department of Hematology, Medical Oncology, \& Pneumology, University Medical Center of the Johannes Gutenberg University, Mainz, Germany.

\section{Author contributions}

C.S.M. was in charge of study design and data analysis and was a major contributor in writing the manuscript. D.T. and B.H. helped with the quality assessment and revised the manuscript. I.S. advised and supervised the statistical analysis. M.T. helped to revise the manuscript. E.M.W. and M.P.R. helped with the study design and revised the manuscript. All authors have read and approved the final manuscript.

\section{Competing interests}

D.T. received honoraria for lectures from Gilead, Pfizer, and MSD, is consultant of advisory board for Gilead, Pfizer, and MSD and received travel support by Abbvie, Astellas, Celgene, Gilead, Jazz, and MSD. The remaining authors have declared that they do not have any conflict of interest.

\section{Additional information}

Correspondence and requests for materials should be addressed to M.P.R.

Reprints and permissions information is available at www.nature.com/reprints.

Publisher's note Springer Nature remains neutral with regard to jurisdictional claims in published maps and institutional affiliations.

Open Access This article is licensed under a Creative Commons Attribution 4.0 International License, which permits use, sharing, adaptation, distribution and reproduction in any medium or format, as long as you give appropriate credit to the original author(s) and the source, provide a link to the Creative Commons license, and indicate if changes were made. The images or other third party material in this article are included in the article's Creative Commons license, unless indicated otherwise in a credit line to the material. If material is not included in the article's Creative Commons license and your intended use is not permitted by statutory regulation or exceeds the permitted use, you will need to obtain permission directly from the copyright holder. To view a copy of this license, visit http://creativecommons.org/licenses/by/4.0/.

(C) The Author(s) 2019 